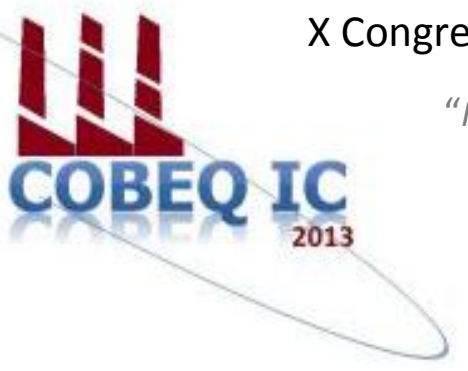

"Influência da pesquisa em Engenharia Química no desenvolvimento tecnológico e industrial brasileiro"

Universidade Federal Rural do Rio de Janeiro Universidade Severino Sombra Vassouras - RJ-Brasil

\title{
ANÁLISE DA BIODECOMPOSIÇÃO DE ÓLEO BRUTO ATRAVÉS DO GRUPO PSEUDOMONAS
}

\author{
J.M.D.A. Câmara ${ }^{1}$; T.B. Fontoura ${ }^{1}$; J.L.S. Melo ${ }^{2}$ e A.M.Lima ${ }^{2}$ \\ (1) Estudante não bolsista de Iniciação Científica - UFRN; \\ (2) Docente - DEQ/CT/UFRN; \\ Departamento de Engenharia Química - Centro de Tecnológica - UFRN, \\ Av. Sen. Salgado Filho, 3000 - Natal, RN - CEP 59078-970 - e-mail: jessica_damiao@ hotmail.com
}

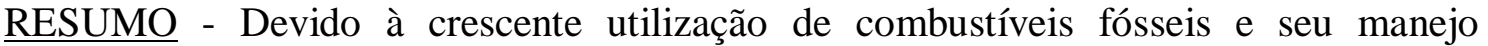
inadequado, a contaminação de solo por hidrocarbonetos tem aumentado nos últimos anos provocando um grave desequilíbrio ao meio ambiente. Visando reduzir esse problema faz-se necessário o estudo de metodologias remediadoras. É com esse intuito que será analisada a eficácia da utilização de microorganismos (grupo pseudomonas), na recuperação de áreas contaminadas por combustíveis fósseis. Esse processo consiste na biorremediação, cujos microorganismos apresentam a capacidade de biotransformar moléculas poluentes em nutrientes para o seu metabolismo, retirando assim os contaminantes do ambiente. O objetivo deste estudo é avaliar a biodegradabilidade do grupo pseudomonas em soluções contendo concentrações de diesel e óleo bruto. $\mathrm{O}$ estudo se dará em cinco etapas, primeiramente com o meio de cultura adequado será analisado o desenvolvimento das bactérias em solo. Na segunda etapa, será feita a análise do solo para identificação e quantificação do grupo. Em seguida, ocorrerá o desenvolvimento de bactérias adaptadas às concentrações de óleo em erlenmeyers. Passada essa etapa de adaptação, as pseudomonas serão inoculadas nos meios contaminados. Com os dados obtidos ao longo da pesquisa, foi possível concluir que o uso do grupo Pseudomonas para a remediação de áreas contaminadas se mostrou um método promissor, pois os microrganismos foram capazes de consumir o carbono, mesmo com o aumento da concentração do substrato, além de apresentar ótimos resultados na produção de biossurfactante.
\end{abstract}

Palavras chave: biorremediação, ramnose, petróleo.

\section{INTRODUÇÃO}

O crescente avanço da tecnologia, desde o inicio da revolução industrial, vem demandando uma quantidade cada vez maior de recursos naturais, o que causa um desequilíbrio no meio ambiente, seja pelo uso indiscriminado ou pela introdução de produtos químicos em determinados locais. E um dos principais problemas é a contaminação por derramamento de petróleo e seus derivados, que têm contribuído para a contaminação do 
solo com hidrocarbonetos em todo planeta. Esse problema é causado principalmente pelas atividades de extração, transporte e refinamento.

Diante disso, observam-se com muita preocupação, os casos de contaminação do solo e água por hidrocarbonetos derivados de petróleo, que mesmo em pequenas concentrações podem constituir um grande perigo à saúde humana e ao meio ambiente (SOUZA et al., 2010). Desta forma, há a necessidade de disponibilizar vários recursos para o desenvolvimento de novas tecnologias de remediação e limpeza.

Os métodos tradicionais, como a contenção e recolhimento através de barreiras flutuantes, a adsorção por materiais naturais ou sintéticos, não se apresentam como um método efetivo, pois estes não promovem a degradação do petróleo.

Uma das técnicas mais estudadas atualmente é a biodegradação, ou seja, a utilização de grupos microbianos capazes de degradar hidrocarbonetos. Este método tornase efetivo, uma vez que, o petróleo é usado como fonte de carbono através dos processos microbianos, resultando na quebra das moléculas em compostos de baixa massa molecular (ZHANG et al., 2005).

Porém, existe um fator que limita a biodegradação dos poluentes; segundo Kronemberg (2007) é a limitada disponibilidade destes compostos aos microrganismos. Já que hidrocarbonetos geralmente se agregam aos componentes do solo, dificultando sua remoção ou degradação.

A biorremediação de solos contaminados com resíduos oleosos depende da capacidade de assimilação desses compostos pelos microrganismos (WETLERTONINI; REZENDE; GRATIVOL, 2010). Muitos microrganismos crescem na presença de contaminantes oleosos produzindo biossurfactantes (VIRAMONTES-RAMOS et al., 2010).

Os biossurfactantes são moléculas que possuem uma parte hidrofóbica e outra hidrofílica, provocando a separação de interfaces com diferentes graus de polaridade, tais como as interfaces óleo/água. Essa propriedade aumenta a solubilidade e a disponibilidade de poluentes hidrofóbicos aos microrganismos, aumentando o potencial de biodegradação (COSTA et al., 2010).

Diversos tipos microbianos são capazes de produzir biossurfactantes, tais como bactérias (PINTO; MARTINS; COSTA, 2009; BUENO, 2008). E um dos compostos biossurfactantes mais investigados são os ramnolipídeos, produzidos pelo grupo Pseudomonas.

\section{MATERIAL E MÉTODOS}

\section{Desenvolvimento Das Bactérias Do Grupo Pseudomonas Em Solo}

Sabendo que o solo é o habitat natural de bactérias desse grupo, utilizou-se $1,5 \mathrm{Kg}$ de areia, a qual foi acondicionada em bandejas plásticas e enriquecida com concentrações conhecidas de petróleo. O solo também foi umedecido com uma solução nutritiva com a seguinte composição: $\mathrm{KH}_{2} \mathrm{PO}_{4} \quad 0,36 \mathrm{mg} / \mathrm{L}$; $\mathrm{MgSO}_{4} \quad 0,120 \mathrm{mg} / \mathrm{L} ; \mathrm{CaCl}_{2} \quad 0,110 \mathrm{mg} / \mathrm{L}$; $\mathrm{NH}_{4} \mathrm{NO}_{3}$ 0,080 mg/L e $\mathrm{MgNO}_{3}$ 0,086 mg/L.

Durante 45 dias foi promovido, em intervalos regulares de cinco dias, a aeração e a exposição ao sol das bandejas que continham o solo. Nesse período, também eram recolhidas amostras que foram submetidas a análises bacteriológicas para identificação e quantificação do grupo pseudomonas.

\section{Análise Do Solo Para Identificação E Quantificação Das Bactérias}

Utilizando erlenmeyers de $250 \mathrm{~mL}$, amostras de $1 \mathrm{~g}$ de areia foram diluídas em $100 \mathrm{~mL}$ de água destilada. Esse sistema foi submetido à agitação de $121 \mathrm{rpm}$ por 24 horas para que o haja o máximo de contato do solo com a água, possibilitando, assim, a máxima transferência dos microrganismos para a água.

Após as 24 horas realizaram-se diluições das amostras, de modo a permitir a inoculação no meio qualitativo Acetamide Agar e no quantitativo Cetrimide Agar. Os inóculos permaneceram por dois dias em uma estufa regulada em $35{ }^{\circ} \mathrm{C}$, conforme especificações do meio.

Posteriormente foi realizada a contagem das colônias que se desenvolveram durante o período de inoculação. 


\section{Preservação Das Bactérias}

As Pseudomonas quantificadas foram repicadas e transferidas para o meio skin milk, concentração de $15 \%$ em grama, onde foram preservadas a uma temperatura de $-10{ }^{\circ} \mathrm{C}$ de modo a permitir sua posterior utilização.

\section{Desenvolvimento Das Bactérias Preservadas}

As bactérias que mostraram melhor adaptação ao solo contaminado com óleo bruto foram utilizadas para a análise do seu crescimento e da produção do biossurfactante.

Desta forma, as bactérias presentes no skin milk foram transferidas para placas petri contendo o meio nutriente Count Plante Agar e colocadas na estufa regulada com uma temperatura de $30{ }^{\circ} \mathrm{C}$ durante 48 horas, para o seu completo desenvolvimento.

\section{Ensaio Para Análise Do Desenvolvimento Das Bactérias E Produção De Biossurfactante}

As colônias desenvolvidas foram repicadas e transferidas para um pré-inóculo com uma solução nutriente de peptona $2 \%$, onde permaneceram em agitação de 200 RPM e $30{ }^{\circ} \mathrm{C}$ durante 24 horas. Após essa etapa, as bactérias já estavam preparadas para os ensaios.

Os experimentos tiveram uma duração de 15 dias. Cada elermeyer continha $50 \mathrm{ml}$ de solução, sendo $1 \mathrm{ml}$ do pré-inóculo e o restante do meio mineral, o qual pode ser encontrado a composição na tabela abaixo, e da fonte de carbono (glicerina). Durante esse tempo, eles foram mantidos no shaker a uma rotação de 200 RPM e $30{ }^{\circ} \mathrm{C}$.

Tabela 1: Composição do meio mineral

\begin{tabular}{cc}
\hline Composto & Concentração $(\mathbf{g} / \mathbf{L})$ \\
\hline $\mathbf{N a N O}_{3}$ & 7,0 \\
$\mathbf{K}_{2} \mathbf{H P O}_{4}$ & 1,0 \\
$\mathbf{K H}_{2} \mathbf{P O}_{4}$ & 0,5 \\
$\mathbf{K C l}$ & 0,1 \\
$\mathbf{M g S O}_{4} \cdot \mathbf{7} \mathbf{H}_{2} \mathrm{O}$ & 0,5 \\
$\mathbf{C a C l}_{\mathbf{2}}$ & 0,01 \\
$\mathbf{F e S O}_{4} \cdot \mathbf{7 H}_{\mathbf{2}} \mathrm{O}$ & 0,01 \\
\hline
\end{tabular}

A cada 24 horas, um elermeyer era retirado e sua solução centrifugada a 3500 RPM por 40 minutos, com o objetivo de separar o sobrenadante e posteriormente realizar as análises.

\section{Determinações Analíticas}

Determinação da concentração celular: A concentração celular foi determinada através da massa seca. Pra tanto, amostras do meio fermentado foram centrifugadas a $3500 \mathrm{rpm}$ por 40 minutos. As células precipitadas foram lavadas e centrifugadas por mais duas vezes em água destilada. Após a última centrifugação, as células foram suspensas em água destilada e transferidas para cápsulas de porcelana previamente taradas e levadas à estufa a $80{ }^{\circ} \mathrm{C}$ por 24 horas. A determinação da massa seca foi feita pela diferença dos pesos final e inicial das cápsulas.

Determinação da concentração de carbono: A concentração de carbono no meio fermentado foi determinada pelo DQO (Demanda Química de Oxigênio), segundo Standard methods (ALPHA, 1998). O método baseia-se na oxidação química da material orgânica, obtida através de um oxidante forte, o dicromato de potássio $\left(\mathrm{K}_{2} \mathrm{Cr}_{2} \mathrm{O}_{7}\right)$ em meio ácido e elevada temperatura.

Determinação da concentração do biossurfactante: A produção de ramnolipídeo foi quantificada colorimetricamente em termos de concentração de ramnose produzida no meio de cultivo, através da análise de 6deoxihexose (CHANDRASEKARAM e BEMILLER, 1980).

Determinação do índice de emulsificação (E24): A estabilidade das emulsões formadas pelo biossurfactante foi avaliada contra diferentes fontes hidrofóbicas. As análises foram realizadas em temperatura ambiente e o índice de emulsificação foi determinado segundo IQBAL et. Al., 1995. O método consiste na adição do hidrocarboneto no caldo livre de células ( $2 \mathrm{~mL}$ de cada) e sua posterior agitação em alta velocidade por 2 minutos. Após 24 horas de repouso, o índice de emulsificação pode ser calculado através da seguinte fórmula: 
E24
$=\left(\frac{\text { altura da camada de emulsão }}{\text { altura total }}\right) \times 100$

\section{RESULTADOS E DISCURSÕES}

\section{Crescimento Microbiano}

Após a inoculação realizada no meio de cultura favorável ao seu desenvolvimento, sob temperatura controlada e agitação adequada, observou-se um comportamento nos valores da concentração celular, conforme indicado na figura 1 .

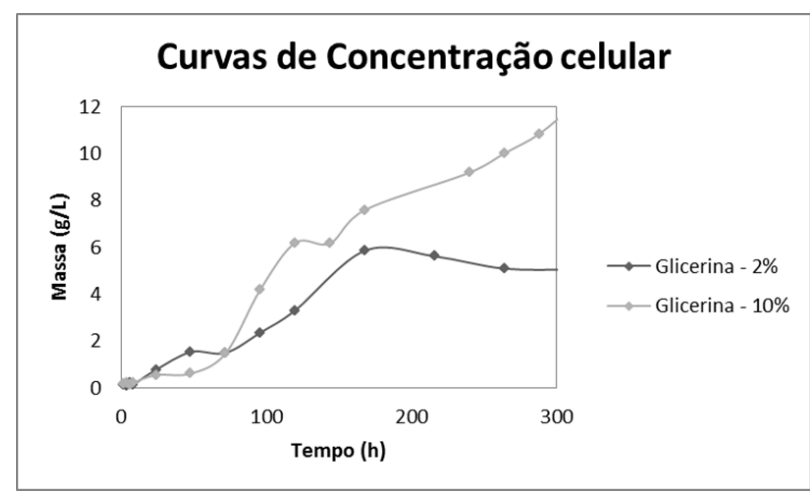

Figura 1 - Efeito da concentração de glicerina no crescimento celular

Os resultados apresentados indicam que o aumento da quantidade de substrato não se mostrou um limitante do crescimento celular. Passado 168 horas de do tempo de fermentação, apenas a concentração de glicerina $1 \%$ apresentou uma estabilização nos valores da proteína celular, diferente da glicerina $5 \%$. Isso ocorreu devido ao esgotamento da fonte de carbono disponível para o consumo microbiano.

Nas duas fermentações foi observada uma fase lag de adaptação, tratando-se de um período de adaptação durante o qual a célula sintetiza as enzimas necessárias ao metabolismo dos componentes presentes no meio.

\section{Produção De Biossurfactante}

Ao analisar a produção de biossurfactante durante o crescimento em glicerina, nas duas concentrações estudadas, observou-se uma baixa produção do tensoativo em baixas concentrações de carbono. Em glicerina $1 \%$, houve um pico de $5,14 \mathrm{mg} / \mathrm{L}$ no tempo de 72 horas, o que pode indicar um provável consumo do produto por parte da bactéria quando o substrato passou a ter concentrações reduzidas.

Como se pode observar na figura 2 , diferente do que ocorreu na glicerina $1 \%$, o aumento da concentração do substrato permitiu uma elevada produção do biossurfactante, que atingiu um valor de 98,87 $\mathrm{mg} / \mathrm{L}$ ao final do tempo de fermentação. Porém, esta ainda encontrava-se em fase de aumento da concentração, indicando que, caso a fermentação continuasse, poderia se conseguir valores mais elevados.

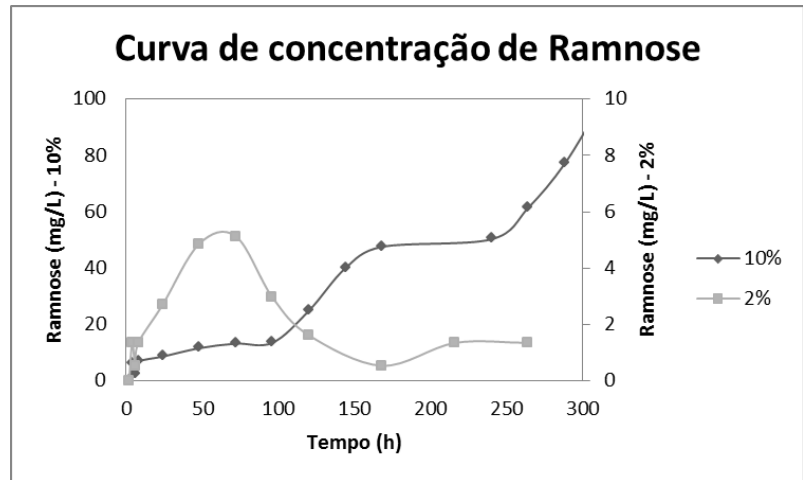

Figura 2 - Produção de biossurfactante em termos de Ramnose

\section{Consumo De Carbono}

O consumo do substrato apresentou um comportamento semelhante nos dois experimentos, tendo uma maior redução na concentração de carbono quando o crescimento celular apresentava sua maior taxa.

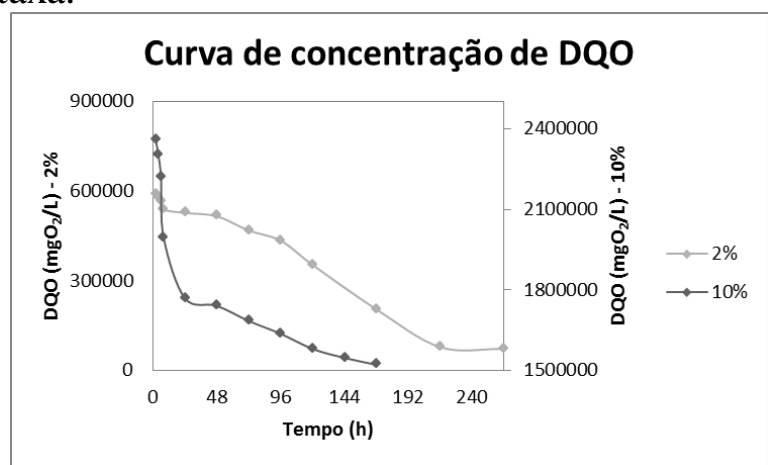

Figura 3 - Curva de consumo do substrato

\section{Determinação Do Índice De Emulsificação}

O estudo de emulsificação foi realizado utilizando o sobrenadante livre de células do cultivo em $5 \%$ de glicerina, onde se obteve a maior quantidade de biossurfactante produzido. Para o estudo foi adicionado óleo bruto no sobrenadante, segundo o procedimento anteriormente descrito. 
Verificou-se que o hidrocarboneto foi emulsificado, apresentado uma taxa de $62,5 \%$ de emulsificação.

\section{CONCLUSÕES}

O processo de biorremediação com o grupo Pseudomonas é um método promissor na limpeza de solos contaminados com hidrocarbonetos. Esta cepa microbiana apresentou ótimos resultados tanto no consumo de carbono quanto na produção de biossurfactantes, possuindo melhores resultados com o aumento da concentração do substrato. Este fator é importante, pois indica que o excesso de carbono não se tornará um fator limitante.

Como as bactérias foram desenvolvidas em solo contaminado com concentrações conhecidas de óleo bruto, sendo esta a única fonte de carbono, pode-se concluir que $\mathrm{o}$ microrganismo está apto a utilizar o hidrocarboneto como nutriente para o seu metabolismo, retirando o contaminante do ambiente.

\section{REFERÊNCIAS}

APHA, AWWA, WEF. Standard methods for the examination of water and wastewater. 20 th edition, 1998 ,

CetemlMCT. Fitorremediação estudo da arte, série Tecnologia Ambiental.< http://www.cetem.gov.br> acesso em 2003-2008.

Larcher, W. Ecofisiologia Vegetal, Rima artes de textos. São Carlos - SP, 2000.Lopes, G.V. C; Carvalho, C. P. J. F; Krieger, N, Biodeterioração, Ataque de Microrganismos a Monumentos Históricos. Ciência Hoje, Rio de Janeiro, n. 200. Vol. 34, p 34 - 39, Dez\} 2 0 0 3 .

ZAGO, C.P. V; DE - POLLI, H; RUMJANEK, N.G, Pseudomonas spp. Fluorescentes - Bactérias Promotoras de Crescimento de Plantas e Biocontroladoras de Fitopatógenos em sistemas de Produção Agrícola. Embrapa. N.127, Dezembro de 2000.

Martins, G.L. Métodos Microbiológicos para determinação do gênero pseudômonas sp. Faculdade de Medicina veterinária e Zootecnia Botucatu - São Paulo, Curso de pós-graduação em Medicina Veterinária. 2003.

\section{AGRADECIMENTOS}

Fiphe

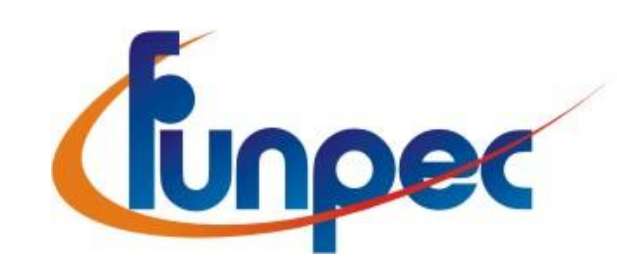

